Case Report

\title{
An Active Isodicentric X Chromosome in a Case of Refractory Anaemia with Ring Sideroblasts Associated with Marked Thrombocytosis
}

\author{
Rosario M. Morales Camacho, ${ }^{1}$ Javier Sanchez, ${ }^{2}$ Irene Marcos Luque, ${ }^{2,3}$ Ricardo Bernal, ${ }^{1}$ \\ Jose F Falantes, ${ }^{1}$ and Jose A Pérez-Simón ${ }^{1}$ \\ ${ }^{1}$ Department of Haematology, Institute of Biomedicine of Seville (IBIS), University Hospital Virgen del Rocío, CSIC, \\ University of Seville, 41013 Seville, Spain \\ ${ }^{2}$ Department of Genetics, Reproduction and Fetal Medicine, Institute of Biomedicine of Seville (IBIS), \\ University Hospital Virgen del Rocío, CSIC, University of Seville, 41013 Seville, Spain \\ ${ }^{3}$ Centre of Biomedical Network Research on Rare Diseases (CIBERER), 41013 Seville, Spain
}

Correspondence should be addressed to Rosario M. Morales Camacho; rosafranco_24@yahoo.es

Received 26 October 2013; Accepted 11 December 2013; Published 30 January 2014

Academic Editors: C. López Ginés and A. Sazci

Copyright (C) 2014 Rosario M. Morales Camacho et al. This is an open access article distributed under the Creative Commons Attribution License, which permits unrestricted use, distribution, and reproduction in any medium, provided the original work is properly cited.

\begin{abstract}
Refractory anaemia with ring sideroblasts and marked thrombocytosis (RARS-T) is a provisional entity in the World Health Organization (WHO) classification. It displays features characteristic of both myelodysplastic syndrome and myeloproliferative neoplasia plus ring sideroblasts $\geq 15 \%$ and marked thrombocytosis. Most patients with RARS-T show a normal karyotype. We report a 76-year-old woman diagnosed with RARS-T (76\% of ring sideroblasts) with JAK2 (V617F) mutation and a load of 30-40\%. Classical and molecular cytogenetic (FISH) studies of a bone marrow sample revealed the presence of isodicentric X chromosome $[(\operatorname{idic}(\mathrm{X})(\mathrm{q} 13)]$. Moreover, HUMARA assay showed the $\operatorname{idic}(\mathrm{X})(\mathrm{q} 13)$ as the active X chromosome. This finding was correlated with the cytochemical finding of ring sideroblasts. To our knowledge, this is the first reported case of an active isodicentric $\mathrm{X}$ in a woman with RARS-T.
\end{abstract}

\section{Introduction}

Refractory anaemia with ring sideroblasts and marked thrombocytosis (RARS-T) is a rare entity which displays features characteristic of both myelodysplastic syndrome and myeloproliferative neoplasia plus ring sideroblasts $\geq 15 \%$ and marked thrombocytosis. Most patients with RARS-T show a normal karyotype in bone marrow sample [1]. Seven years after its incorporation into the 2001 World Health Organization (WHO) classification [2], RARS-T still remains a provisional entity under the category of myelodysplastic/myeloproliferative neoplasm, unclassifiable [3].

An isodicentric X chromosome with breakpoints in Xq13 $(\mathrm{idic}(\mathrm{X})(\mathrm{q} 13))$ is a rare cytogenetic abnormality with an extra dose of Xpter-q13 and loss of the Xq13-qter region. Currently, controversy exists regarding whether $\operatorname{idic}(\mathrm{X})(\mathrm{q} 13)$ is active or inactive and whether or not there is any correlation with the cytochemical finding of ring sideroblasts [4].

\section{Case Report}

We report a 76-year-old female presenting with RARS-T and $\operatorname{idic}(\mathrm{X})(\mathrm{q} 13)$ in bone marrow cells. She presented with anaemia (mean corpuscular volume, $103 \mathrm{fl}$; haemoglobin, $9.2 \mathrm{~g} / \mathrm{dL}$ ), leukocytes of $11.7 \times 10^{9} / \mathrm{L}$, and a thrombocytosis of $709 \times 10^{9} / \mathrm{L}$. The patient was diagnosed with RARS-T (76\% of ring sideroblasts) with JAK2 (V617F) mutation and a load of $30 \%-40 \%$. A cytogenetic analysis of the bone marrow revealed two clones, one with an isodicentric $\mathrm{X}$ and another with a normal chromosomal complement: 46,X,idic(X)(q13)[4]/46,XX[16] (Figure 1(a)). HUMARA assay showed the $\operatorname{idic}(\mathrm{X})(\mathrm{q} 13)$ as the active $\mathrm{X}$ chromosome. In situ fluorescent hybridisation with a DXZ1 centromere probe (Vysis Downers Grove, IL, USA) (Figure 1(b)) and a whole chromosome painting (WCP) X chromosome probe (Vysis Downers Grove, IL, USA) (Figure 1(c)) showed two 


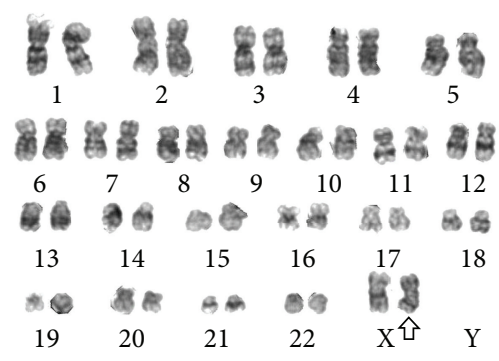

(a)

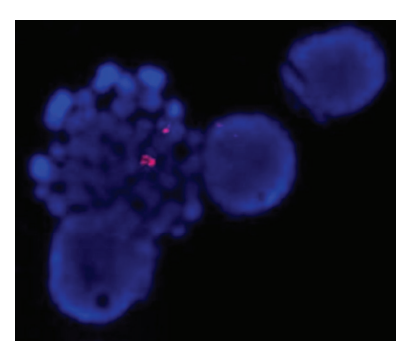

(b)

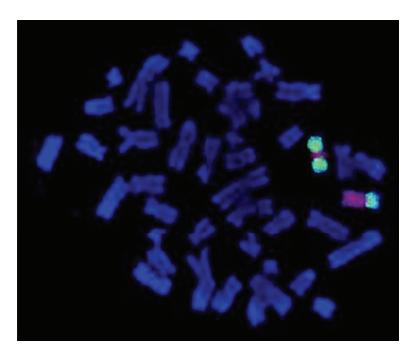

(c)

FIGURE 1: (a) G-banded karyotype of the bone marrow cells showed a 46,X,idic(X)(q13)[4]/46,XX[16]. The arrow indicates the isodicentric $\mathrm{X}$ chromosome. (b) FISH analysis in metaphase cell with CEP X probe showed two centromeres on the idic(X), red signals. (c) Hybridisation on metaphase cell with WCP Xp (green signal) and WCP Xq probes (red signal) showed a normal X chromosome and an idic(X) with a red signal $(\mathrm{Xq})$ between two green signals $(\mathrm{Xp})$.

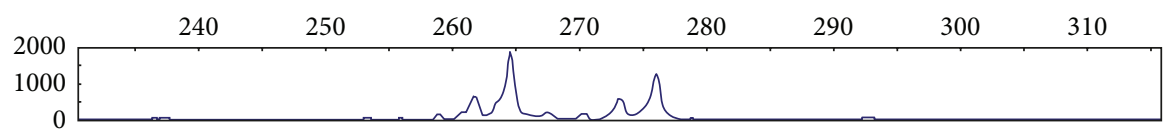

(a)

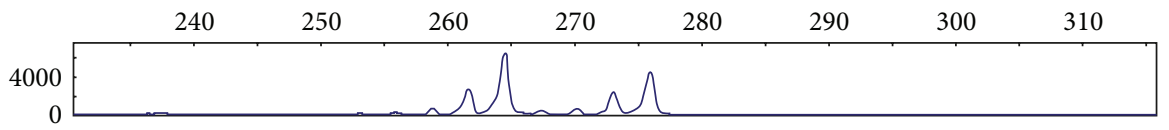

(b)

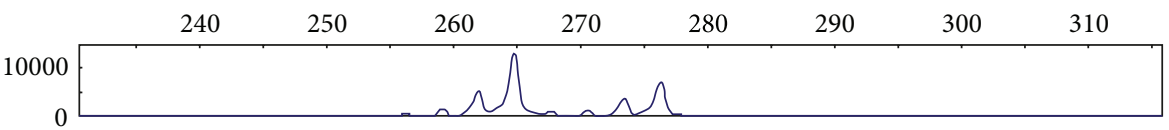

(c)

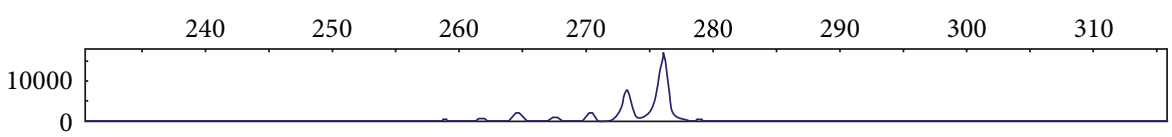

(d)

FIGURE 2: HUMARA analysis. The panels show size-separation of PCR products by capillary electrophoresis. The $x$-axes show the sizes in base pairs and the $y$-axes the fluorescence activity. Each peak corresponds to one allele of the amplified microsatellite. Controls (a) and (b): random methylation pattern: no difference observed between the undigested sample (a) and digested sample (b). Patients (c) and (d). (c) Genomic DNA: two alleles are visible at 264 and 276 base pairs. Semiquantitative PCR showed that the 264 -base pair allele was located on the $\operatorname{idic}(\mathrm{X})(\mathrm{q} 13)$, visible as a peak height ratio of 1.86. (d) After digestion, only the 276-base pair peak was present, showing that the isodicentric chromosome was active.

centromeres and the duplication of Xpter-q13. Cytogenetic analysis performed in a 72-hour lymphocyte culture obtained from whole blood stimulated with PHA was normal.

A CGH array performed with human CGH 720K Whole Genome Tiling v3.0 array HG 18 (Nimblegen, Roche) did not detect any abnormality in the number of copies of the $\mathrm{X}$ chromosome, which may be due to the fact that $\operatorname{idic}(X)(q 13)$ was only present in a small subclone (4/20 metaphases).

The X chromosome inactivation (XCI) tests consisted of examining the methylation state of the human androgen receptor gene (HUMARA, Xq12), as described by Allen et al. [5]. This analysis allows the identification of the active $X$ chromosome by analysing the methylation state of a highly polymorphic and typically heterozygotic region (CAG)n at the $5^{\prime}$ end of this gene, in the excess region of the isodicentric chromosome. Bone marrow samples were separated using an automated DNA sequencer (ABI3730, Life Technologies, Carlsbad, CA) and analysed by GeneMapper software (Life Technologies) for peak positioning and calculating the peak areas. These data were used to calculate the XCI ratio.

The number of CAG tandem repeats allowed differentiating the allele corresponding to the $\operatorname{idic}(X)(q 13)$ from the allele pertaining to the normal $\mathrm{X}$ chromosome. Initially, we performed a semiquantitative PCR analysis of the genomic DNA on a capillary electrophoresis system, obtaining a fluorescence signal for each allele on the locus for the HUMARA gene, shown as a peak and area under the curve. Since the amplified region was present in two copies on the isodicentric $\mathrm{X}$ chromosome, the assay showed a higher peak with a ratio close to 2 as compared to the height of the two separate alleles (Figure 2(c)). The XCI patterns revealed that the $\operatorname{idic}(\mathrm{X})(\mathrm{q} 13)$ belonged to the $100 \%$ active X chromosome (Figure 2(d)). 
The genomic DNA from a healthy volunteer served as a control to validate the experiment (Figures 2(a) and 2(b)).

\section{Discussion}

The $\operatorname{idic}(\mathrm{X})(\mathrm{q} 13)$ is a rare cytogenetic abnormality generally associated with ring sideroblasts in neoplastic myeloid pathologies [6, 7]. Several authors $[4,6,8]$ suggested that the $A B C B 7$ gene, located on the deleted $\mathrm{Xq13}$ region in $\operatorname{idic}(\mathrm{X})$ positive cases and involved in the transportation of iron from mitochondria to cytosol in the erythroblasts, is lost exclusively on the active $\mathrm{X}$ chromosome. Moreover, a rare inherited X-linked sideroblastic anemia with spinocerebellar ataxia, characterized by anaemia with mitochondrial iron accumulation in the bone marrow erythroblasts, is caused by mutations in $A B C B 7$ gene. These defects of $A B C B 7$ would be the underlying cause of the common ring sideroblasts in these patients.

It is also feasible that the consequence of the presence of an $\operatorname{idic}(X)(q 13)$ would be different if it occurs in the active or inactive X chromosome. More than 30 cases of $\operatorname{idic}(X)(q 13)$ have been reported. In 14 cases an analysis of $\mathrm{X}$ inactivation was performed $[4,6,9,10]$, but only in two cases there are data available regarding the presence of ring sideroblasts. In addition, seven cases where the $\operatorname{idic}(X)(q 13)$ was the inactive $\mathrm{X}$ chromosome were considered as myeloproliferative neoplasias $[4,9]$ without ring sideroblasts.

In summary, in patients with myeloid malignancies and $\operatorname{idic}(\mathrm{X})(\mathrm{q} 13)$, an analysis of methylation status of X chromosome would be recommended for determining any preferential inactivation. Further studies are needed to assess whether the activation state of $\operatorname{idic}(\mathrm{X})(\mathrm{q} 13)$ is correlated with the presence of ring sideroblasts and, as such, with the underlying pathology.

\section{Conflict of Interests}

The authors declare that there is no conflict of interests regarding the publication of this paper.

\section{References}

[1] J. M. Raya, L. Arenillas, A. Domingo et al., "Refractory anemia with ringed sideroblasts associated with thrombocytosis: comparative analysis of marked with non-marked thrombocytosis, and relationship with JAK2 V617F mutational status," International Journal of Hematology, vol. 88, no. 4, pp. 387-395, 2008.

[2] B. J. Bain, J. W. Vardiman, M. Imbert, and R. Pierre, "Myelodisplastic/myeloproliferative disease, unclassifiable," in WHO Classification of Tumours of Haematopoietic and Lymphoid Tissues, E. S. Jaffe, N. L. Harris, H. Stein, and J. W. Vardiman, Eds., pp. 58-59, 2001.

[3] J. W. Vardiman, J. M. Bennett, B. J. Bain, I. Baumann, J. Thiele, and A. Orazi, "Myelodysplastic/myeloproliferative neoplasm, unclassifiable," in WHO Classification of Tumours of Haematopoietic and Lymphoid Tissues, S. H. Swerdlow, E. Campo, N. L. Harris et al., Eds., pp. 85-86, Lyon, France, 2008.

[4] K. Paulsson, C. Haferlach, C. Fonatsch et al., "The idic(X)(q13) in myeloid malignancies: breakpoint clustering in segmental duplications and association with TET2 mutations," Human Molecular Genetics, vol. 19, no. 8, Article ID ddq024, pp. 1507$1514,2010$.

[5] R. C. Allen, H. Y. Zoghbi, A. B. Moseley, H. M. Rosenblatt, and J. W. Belmont, "Methylation of HpaII and HhaI sites near the polymorphic CAG repeat in the human androgen-receptor gene correlates with X chromosome inactivation," American Journal of Human Genetics, vol. 51, no. 6, pp. 1229-1239, 1992.

[6] G. W. Dewald, M. Brecher, L. B. Travis, and P. J. Stupca, "Twenty-six patients with hematologic disorders and X chromosome abnormalities. Frequent $\operatorname{idic}(\mathrm{X})(\mathrm{q} 13)$ chromosomes and Xq13 anomalies associated with pathologic ringed sideroblasts," Cancer Genetics and Cytogenetics, vol. 42, no. 2, pp. 173$185,1989$.

[7] J. Dierlamm, L. Michaux, A. Criel et al., "Isodicentric (X)(q13) in haematological malignancies: presentation of five new cases, application of fluorescence in situ hybridization (FISH) and review of the literature," British Journal of Haematology, vol. 91, no. 4, pp. 885-891, 1995.

[8] K. Sato, Y. Torimoto, T. Hosoki et al., "Loss of ABCB7 gene: pathogenesis of mitochondrial iron accumulation in erythroblasts in refractory anemia with ringed sideroblast with isodicentric $(\mathrm{X})(\mathrm{q} 13)$," International Journal of Hematology, vol. 93, no. 3, pp. 311-318, 2011.

[9] P. Temperani, P. Zucchini, G. Emilia, S. Sacchi, L. Selleri, and U. Torelli, "Isodicentric X chromosome in myeloproliferative disorders," Acta Haematologica, vol. 81, no. 3, pp. 152-154, 1989.

[10] K. A. Rack, J. Chelly, R. J. Gibbons et al., "Absence of the XIST gene from late-replicating isodicentric X chromosomes in leukaemia," Human Molecular Genetics, vol. 3, no. 7, pp. 1053-1059, 1994. 


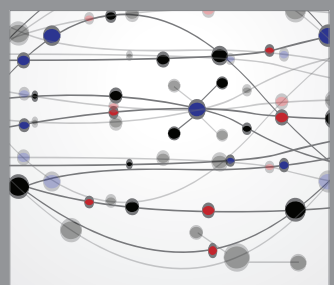

The Scientific World Journal
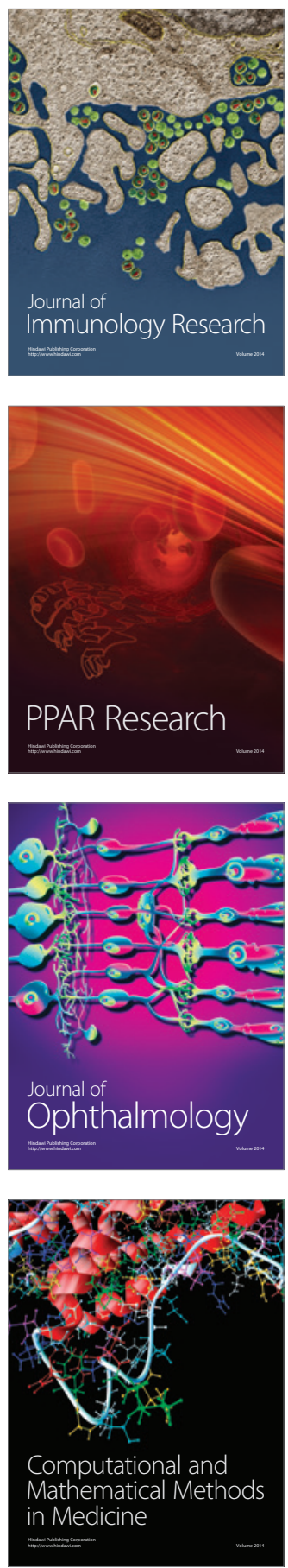

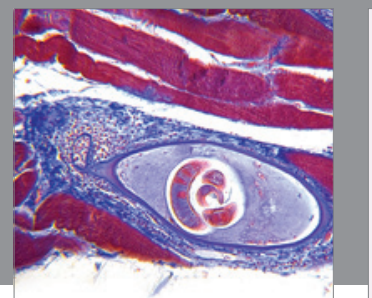

Gastroenterology

Research and Practice
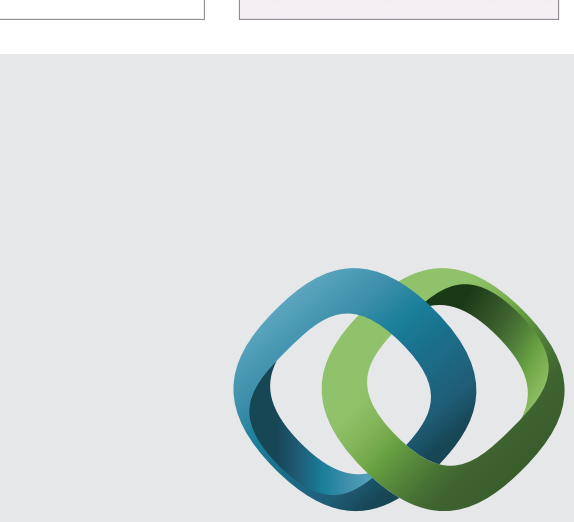

\section{Hindawi}

Submit your manuscripts at

http://www.hindawi.com
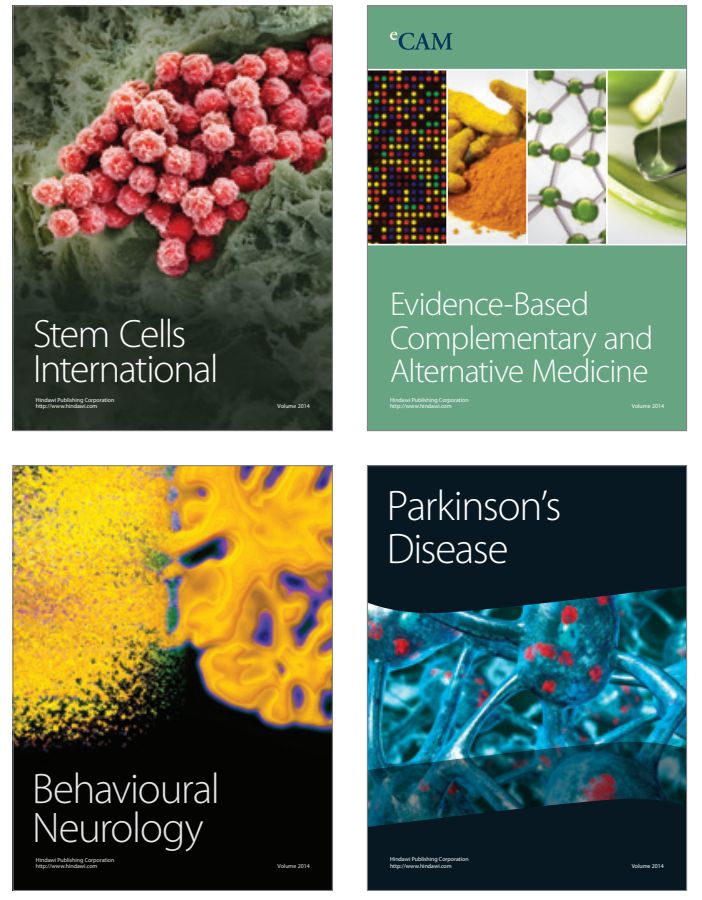
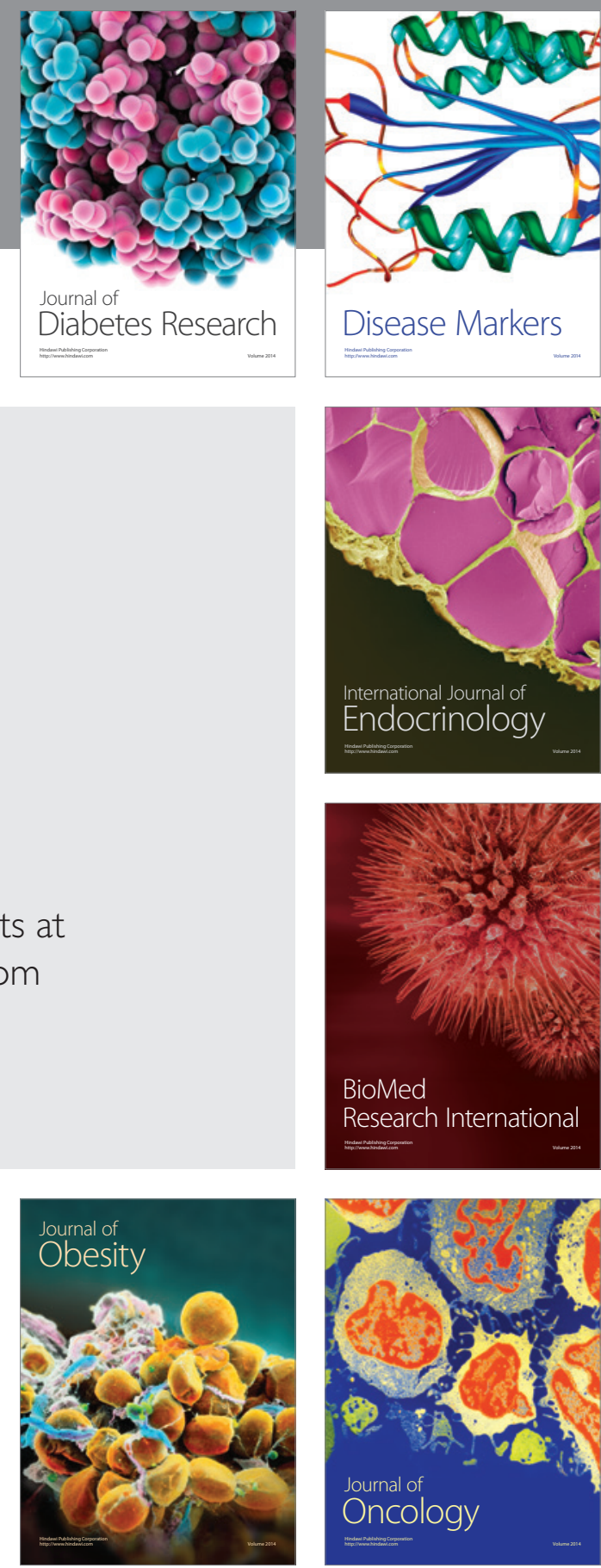

Disease Markers
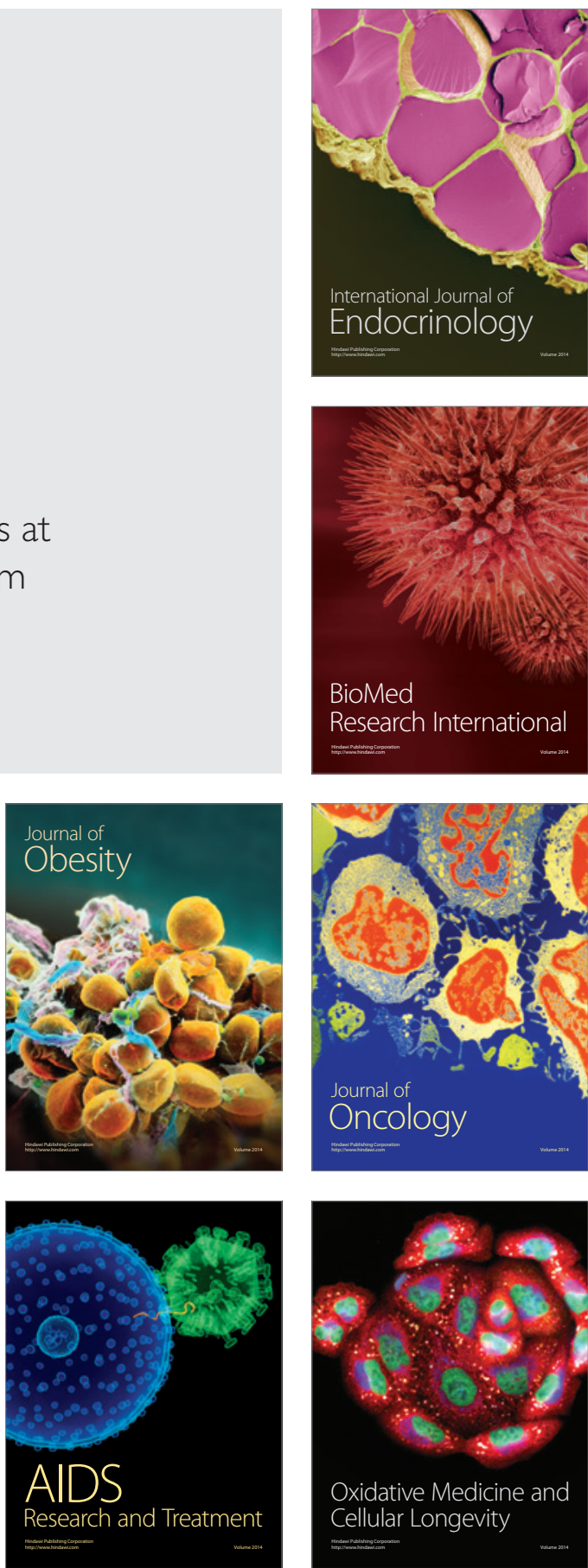